\title{
PENATAAN UTILITAS DI KORIDOR SEI RAMPAH
}

\author{
Dwira Nirfalini Aulia ${ }^{1}$, Fauzi Al Huda ${ }^{2}$ \\ ${ }^{1,2}$ Program Studi Magister Teknik Arsitektur Fakultas Teknik Universitas Sumatera Utara \\ Jl. Perpustakaan St. J07 Building, Medan, 20155, Indonesia \\ *Email: 'dwira_aulia@yahoo.com; ${ }^{2}$ arsitekfauzi@gmail.com
}

\begin{abstract}
ABSTRAK
Penataan utilitas di Koridor Sei Rampah sangat memberikan pengaruh terhadap koridor jalan tersebut. Terkait dengan aspek utilitas, pemerintah daerah setempat sudah memilki kebijakan terkait penataan utilitas. Perencanaan infrastruktur sebuah wilayah sangat di dukung dengan adanya keberhasilan menyangkut penataan utilitas. Utilitas dirasa sangat diperlukan karena merupakan hal penting dalam penataan sebuah kota. Jika utilitas tidak di tata dengan sebaik mungkin dikhawatirkan akan menimbulkan genangan air yang terjadi pada saluran kota. Dan yang paling di khawatirkan genangan air ini apabila terus di biarkan akan menimbulkan penyakit pada masyarakat setempat dan sebagian orang yang melintasi koridor tersebut. Pertumbuhan ekonomi sebuah daerah akan bergerak naik seiring majunya penataan utilitas di daerah tersebut.
\end{abstract}

Kata Kunci: Penataan, Utilitas, Koridor Sei Rampah.

\section{PENDAHULUAN}

Pada aspek utilitas, disini akan membahas tentang saluran drainase, dan akan dijelaskan sesuai dengan pembagian zona koridor Sei Rampah, hal ini dikarenakan terdapatnya perbedaan saluran drainase dari hasil pengamatan dilapangan terhadap masing-masing zona.

\section{Segmen I}

Saluran drainase yang ada saat ini di Kawasan Perkotaan Sei Rampah masih sangat sedikit. Belum seluruhnya jalan yang ada dilengkapi dengan saluran drainase. Jalan - jalan yang sudah memiliki saluran drainase umumnya hanya terdapat pada jalan-jalan utama di pusat kota atau jalan lintas, bahkan kondisinya tidak berfungsi dengan baik. Bentuk saluran drainase terbuka dan tertutup dengan kedalaman $50 \mathrm{~cm}$, membuat saluran drainase dipenuhi oleh banyak sampah dan tidak berfungsi secara maksimal. Ditinjau dari segi fungsi, saluran drainase yang ada juga hanya difungsikan sebagai pembuangan air hujan dari badan jalan dan bangunan pertokoan. Sedangkan untuk saluran drainase air kotor, pembuangan diarahkan ke belakang bangunan yaitu kearah pemukiman penduduk. Kondisi yang demikian menimbulkan permasalahan pada area koridor seperti rawan genangan air dan banjir ketika musim penghujan turun, bahkan tidak musim penghujan pun area tersebut sering terjadi genangann air, akibat pembuangan air kotor. Keadaan ini sangat bertolak belakang dengan Permen $\mathrm{Pu}$ No 12/PRT/M/2014 tentang penyelenggaraan sistem drainase perkotaan, dimana saluran drainase kota merupakan saluran primer untuk mengalirkan air buangan dari kawasan ke badan air penerima. Oleh karena itu sangat diperlukan suatu pedoman terkait sistem drainase air yang difungsikan sebagai jalur pembuangan air kotor dan air hujan hingga kejelasan terkait penerapan dari bentuk saluran drainase, agar fungsinya dapat berjalan dengan semestinya. Tujuannya adalah tercipta lingkungan kota yang sehat dan nyaman, bebas dari genangan air. 


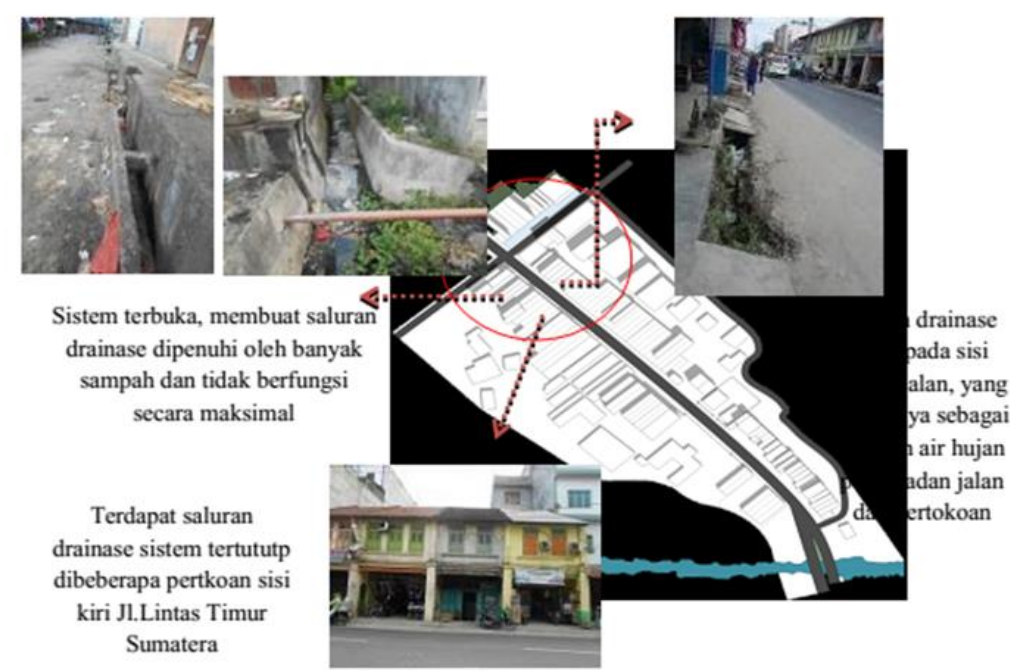

Gambar 1. Saluran drainase Segmen 1 Koridor Sei Rampah

\section{Segmen II}

Pada segmen II terdapat saluran drainase terbuka dan tertutup dengan fungsi saluran sebagai resapan air hujan yang barasal dari jalan dan bangunan. Sama halnya dengan segmen 1, untuk saluran drainase air kotor diarahkan kebelakang pertokoan/kearah pemukiman kota. Keadaaan inilah yang sering menyebabkan terjadi genangan air, terutama disela-sela pertokoan bahkan hingga mengeluarkan bau, adanya perbedaan jenis saluran drainase pada jalur koridor kota Sei rampah menimbulkan Permasalahan lain yang ditimbulkan pada segmen II adalah tidak konsistennya penerapan jenis saluran drainase sehingga merusak keindahan visual ruang kota. Oleh karena itu sangat penting dibuatnya suatu panduan perancangan koridor jalur Kota Sei Rampah, dengan tujuan terciptanya ruang kota, yang sehat, aman dan nyaman bagi semua kalangan masyarakat.

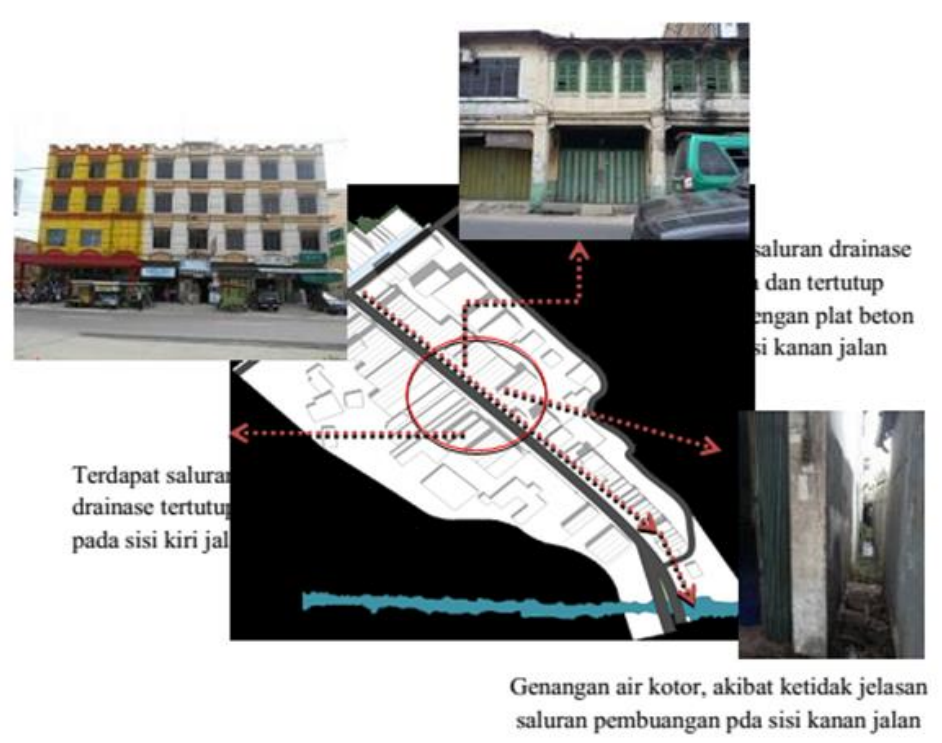

Gambar 2. Saluran drainase Segmen 1 Koridor Sei Rampah 


\section{Segmen III}

Keadaan saluran drainase pada segmen III, semakin memperjelas jalur drainase yang ada di sepanjang jalur koridor Sei Rampah. Hal ini terlihat dari terputusnya saluran drainase pada sisi kanan jalan, yang seharusnya menuju sungai sebagai badan air penerima. Keadaan ini sangat bertolak belakang dengan RUTRK Kota Sei Rampah, untuk jaringan drainase kota pembuangan air langsung diarahkan ke aliran sungai. Lain halnya dengan saluran drainase pada sisi kiri jalan, yang saluran drainase nya jelas hingga ke badan air penerima. Oleh karena itu sangat dibutuhkan sebuah pedoman perencanaan koridor terutama yang berkaitan dengan utilitas sistem drainase. Tujuan dari dibuatnya pedoman ini adalah agar jalur jalan koridor kota Sei Rampah memiliki kejelasan saluran

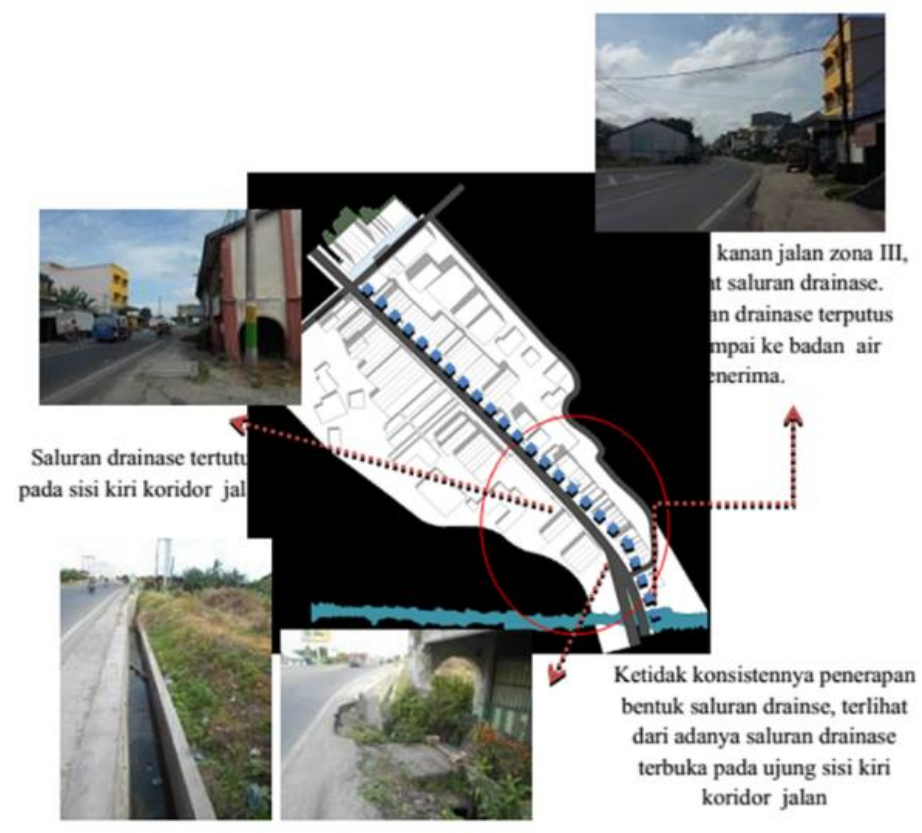

Gambar 3. Saluran drainase Segmen 1 Koridor Sei Rampah

\section{METODE PENELITIAN}

Penulisan ini meliputi Substansi RTRW Kabupaten Serdang Bedagai yang mencakup rencana struktur ruang wilayah Kabupaten yang meliputi rencana sistem perkotaan, rencana sistem jaringan transportasi, rencana sistem jaringan energi, rencana sistem jaringan telekomunikasi, rencana sistem jaringan sumberdaya air, serta rencana sistem jaringan prasarana lingkungan kemudian Kemudian peraturan yang ada dianalisa dengan membandingkan kondisi yang ada saat ini di sepanjang Koridor Sei Rampah dan menghubungkannya dengan aturan-aturan yang ada, yang selanjutnya akan di analisa dan dilakukan cara untuk mencapai sebuah solusi ataupun sebuah panduan penataan utilitas di Koridor Sei Rampah.

\section{HASIL DAN PEMBAHASAN}

Permasalahan terkait aspek utilitas saluran drainase, akan dijelaskan sesuai dengan pembagian zona koridor Koridor Sei Rampah. Lintas sumatera, hal ini dikarenakan terdapatnya perbedaan saluran drainase dari hasil pengamatan dilapangan terhadap masing-masing zona.

\section{Segmen I}

Jaringan drainase yang ada saat ini di Kawasan Perkotaan Sei Rampah masih sangat sedikit. Belum seluruhnya jalan yang ada dilengkapi dengan saluran drainase. Jalan - jalan yang sudah memiliki saluran drainase umumnya hanya terdapat pada jalan-jalan utama di pusat kota atau jalan lintas, bahkan kondisinya tidak berfungsi dengan baik. Bentuk saluran drainase terbuka dan tertutup dengan kedalaman $50 \mathrm{~cm}$, 
membuat saluran drainase dipenuhi oleh banyak sampah dan tidak berfungsi secara maksimal. Ditinjau dari segi fungsi, saluran drainase yang ada juga hanya difungsikan sebagai pembuangan air hujan dari badan jalan dan bangunan pertokoan. Sedangkan untuk saluran drainase air kotor, pembuangan diarahkan ke belakang bangunan yaitu kearah pemukiman penduduk. Kondisi yang demikian menimbulkan permasalahan pada area koridor seperti rawan genangan air dan banjir ketika musim penghujan turun, bahkan tidak hanya musim penghujan pun area tersebut sering terjadi genangan air, akibat pembuangan air kotor.

Keadaan ini sangat bertolak belakang dengan Permen Pu No 12/PRT/M/2014 tentang penyelenggaraan sistem drainase perkotaan, dimana seluran drainase kota merupakan saluran primer untuk mengalirkan air buangan dari kawasan ke badan air penerima. Oleh karena itu sangat diperlukan suatu pedoman terkait sistem drainase air yang difungsikan sebagai jalur pembuangan air kotor dan air hujan hingga kejelasan terkait penerapan dari bentuk saluran drainase, agar fungsinya dapat berjalan dengan semestinya. Sejalan dengan Teori Dr. Ir. Suripin, M. Eng. (2004; 7) drainase mempunyai arti mengalirkan, menguras, membuang, atau mengalihkan air. Secara umum, drainase didefinisikan sebagai serangkaian bangunan air yang berfungsi untuk mengurangi dan/ atau membuang kelebihan air dari suatu kawasan atau lahan, sehingga lahan dapat difungsikan secara optimal.

Solusi yang dapat diidentifikasi dari kasus Koridor Kota Sei Rampah ditinjau dari aspek drainase adalah sebagai berikut:

(1) Memperdalam galian drainase menjadi 1 $\mathrm{m} 2$

(2) Membuat sumur resapan tepat di bawah saluran drainase dengan kedalaman $1 \mathrm{~m} 2$ dan lebar $40 \mathrm{~cm}$

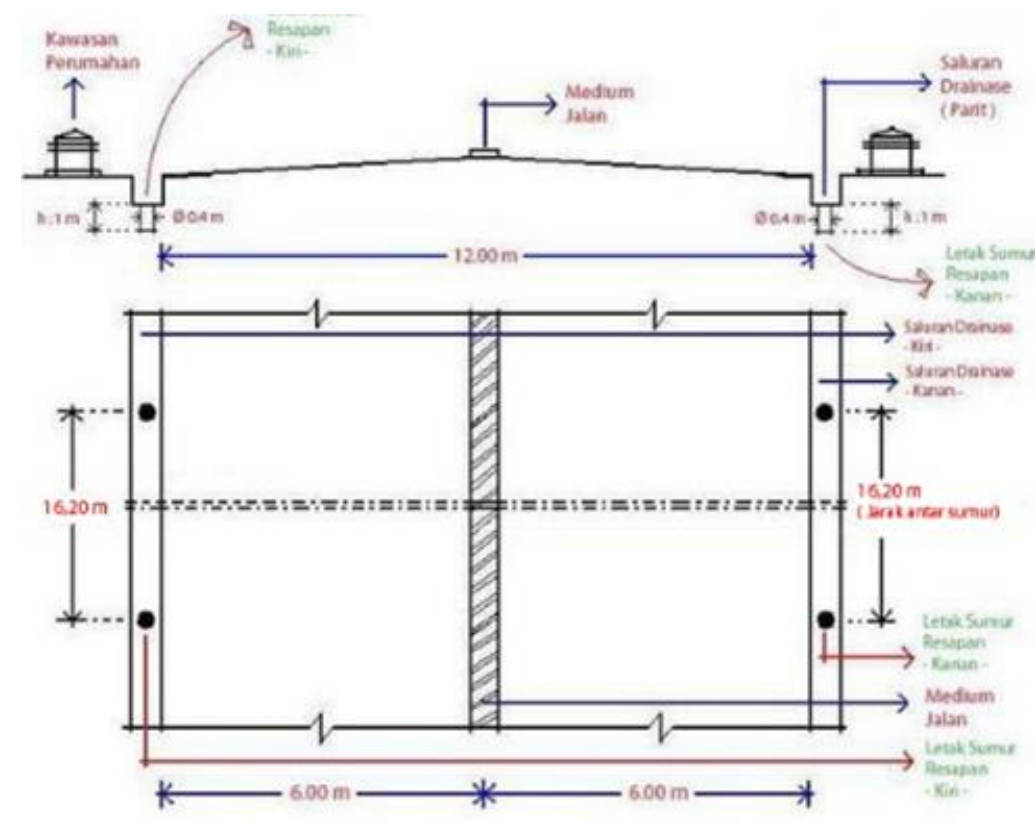

Gambar 4. Ilustrasi Penataan drainase

Sumber: https://gambar+saluran+drainase \&espv=2\&biw=1366\&bih=662\&source=lnms $\&$ tbm=isch 


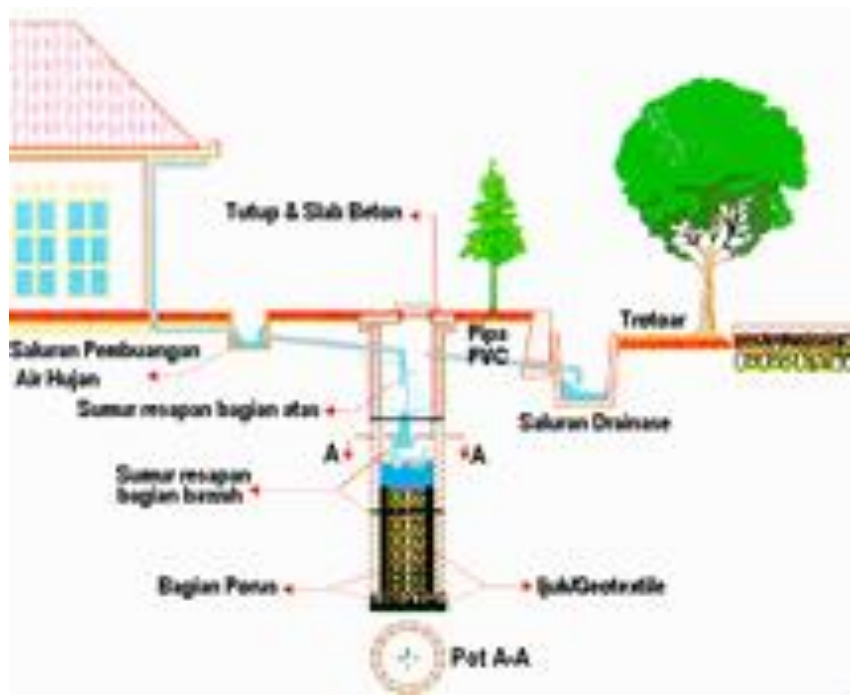

Gambar 5. Ilustrasi Penataan drainase

Sumber: https://gambar+saluran+drainase \&espv=2\&biw=1366\&bih=662\&source=lnms \&tbm=isch

\section{Segmen II}

Pada segmen II terdapat saluran drainase terbuka dan tertutup dengan fungsi saluran sebagai resapan air hujan yang barasal dari jalan dan bangunan. Sama halnya dengan segmen 1, untuk saluran drainase air kotor diarahkan kebelakang pertokoan/kaarah pemukiman kota. Keadaaan inilah sering menyebabkan terjadi genangan air, terutama disela-sela pertokoan bahkan hingga mengeluarkan bau adanya perbedaan jenis saluran dranase pada jalur koridor kota Sei rampah Permasalahan lain yang ditimbulkan pada segmen II adalah tidak konsistennya penerapan jenis saluran drainase sehingga merusak keindahan visual ruang kota. Oleh karena itu sangat penting dibuatnya suatu panduan perancangan koridor jalur Kota Sei Rampah, dengan tujuan terciptanya ruang kota, yang sehat, aman dan nyaman bagi semua kalangan masyarakat. Solusi yang dapat diidentifikasi dari kasus Koridor Kota Sei Rampah ditinjau dari aspek drainase adalah sebagai berikut:

1. Membuat Bendung Setempat Untuk Memperlambat Aliran.

2. Mengalirkan saluran drainase ke kolam penangkap sedimen kemudian mengalirkan nya ke sungai.

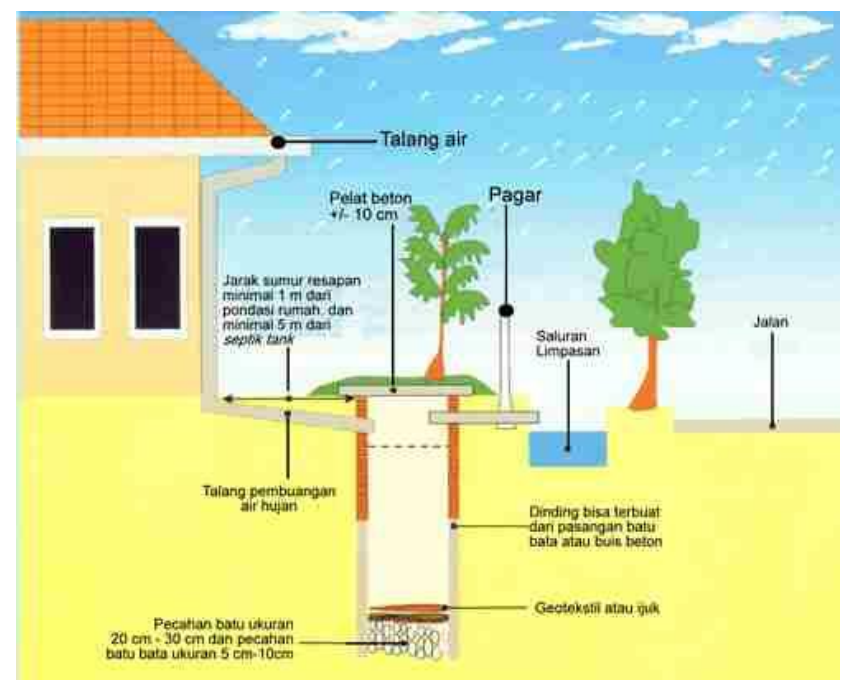

Gambar 6. Ilustrasi Penataan drainase

https://gambar+saluran+drainase \&espv=2\&biw=1366\&bih=662\&source=lnms\&tbm=isch 


\section{Segmen III}

Keadaan saluran drainase pada segmen III, semakin memperjelas jalur drainase yang ada di sepanjang jalur koridor Kota Sei Rampah. Hal ini terlihat dari terputusnya saluran drainase pada sisi kanan jalan, yang seharusnya menuju sungai sebagai badan air penerima. Keadaan ini sangat bertolak belakang dengan RUTRK Kota Sei Rampah, untuk jaringan darinase kota pembuangan air langsung diarahkan ke aliran sungai. Lain halnya dengan saluran drainase pada sisi kiri jalan, yang saluran drainase Terputus. Oleh karena itulah sangat dibutuhkan sebuah pedoman perencanaan koridor terutama yang berkaitan dengan utilitas sistem drainase. Tujuan dari dibuatnya pedoman ini adalah agar jalur jalan koridor kota sei rampah memiliki kejelasan saluran drainase,sehingga tercipta suatu ruang kota yang sehat dan nyaman.

Solusi yang dapat diidentifikasi dari kasus Koridor Kota Sei Rampah ditinjau dari aspek drainase adalah sebagai berikut: Menyambung saluran drainase yang terputus di koridor Sei Rampah agar saluran air dapat terus mengalir hingga selanjut nya saluran drainase tersebut di alirkan ke sungai.

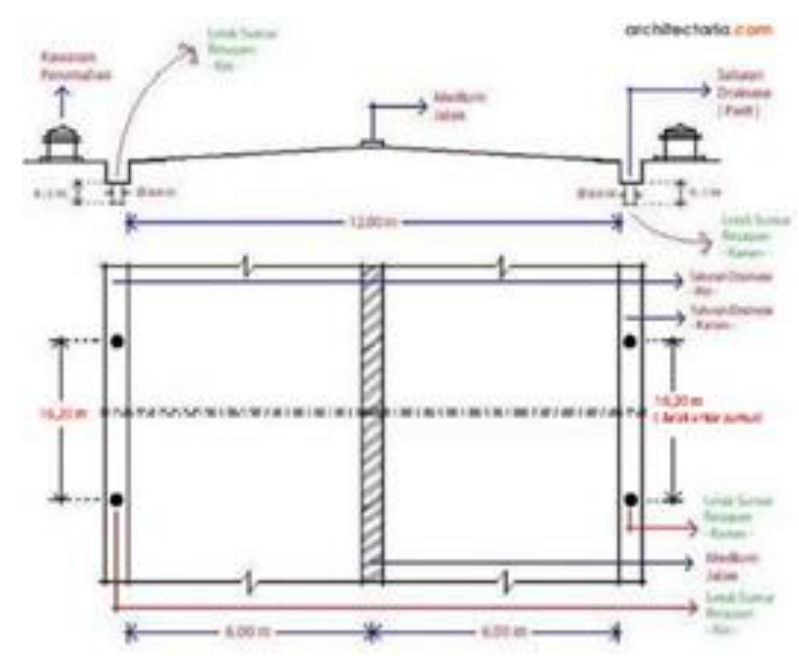

Gambar 8. Ilustrasi Penataan drainase

Sumber: https://gambar+saluran+drainase \&espv=2\&biw=1366\&bih $=662 \&$ source $=1$ nms $\&$ tbm $=i s c h$

\section{KESIMPULAN}

1. Penataan utilitas sangat menentukan keberhasilan perencanaan sebuah kota.

2. Utilitas di nilai sangat penting untuk mencegah genangan air dan banjir.

3. Peran masyarakat sangat di butuhkan agar utilitas dapat berfungsi dengan baik.

4. Pemerintah harus cepat menyikapi jika terjadi permasalahan utilitas di suatu kota.

\section{Daftar Pustaka}

Permen $\mathrm{Pu}$ No 12/PRT/M?2014 tentang penyelenggaraan sistem drainase perkotaan.

RTRW Kabupaten Serdang Bedagai yang mencakup rencana struktur ruang wilayah Kabupaten yang meliputi rencana sistem perkotaan.
Dr. Ir. Suripin, M. Eng. (2004; 7), drainase mempunyai arti mengalirkan, menguras, membuang, atau mengalihkan air.

https://gambar+saluran+drainase \&espv=2\&biw $=1366 \&$ bih $=662 \&$ source $=1 \mathrm{nms} \& \mathrm{tbm}=\mathrm{isc}$ $\mathrm{h}$ 